\title{
Effects of Pretreatment on the Soil Aging Behavior of Rice Husk Fibers/Polyvinyl Chloride Composites
}

\begin{abstract}
Lei Wang, ${ }^{a}$ Chunxia He, ${ }^{a, *}$ and Xingxing Yang ${ }^{b}$
The application of rice husk fibers (RHFs) to reinforce wood plastic composites has received appreciable attention. However, good interfacial adhesion is important for actual applications. Pretreatment methods can reduce the hydroxyl groups in plant fibers in order for them to bond with the plastic matrix. In this research, RHFs were pretreated by four methods: hydrothermal treatment $(\mathrm{HT})$, microwave treatment (MT), alkali treatment (AT), and benzoylation treatment (BT). The effects of the four pretreatment methods on aging behavior of RHFs/polyvinyl chloride (PVC) composites was studied with simulated soil-accelerated aging conditions. Accelerated-soil aging caused the physical and mechanical properties of the composites to deteriorate. The ultimate performance of the composites was improved by the pretreated RHFs. The effectiveness ranking of the pretreatment methods was: benzoylation-treated RHFs reinforced PVC (BRRP) > alkali-treated RHFs reinforced PVC (ARRP) > hydrothermal-treated RHFs reinforced PVC (HRRP) > microwave-treated RHFs reinforced PVC (MRRP) > untreated RHFs reinforced PVC (URRP).
\end{abstract}

Keywords: Rice husk fibers; Interfacial adhesion; Surface structure; Ultimate performance

Contact information: a: College of Engineering Nanjing Agricultural University, Nanjing 210031, China; b: School of Machinery and Electricity, Southeast University Cheng Xian College, Nanjing 210088, China;

* Corresponding author: chunxiahe@ hotmail.com

\section{INTRODUCTION}

Wood plastic composites (WPCs) are used in many applications, such as outdoor equipment (Mei et al. 2017). The development of composites will be important in the future (Koohestani et al. 2017). WPCs are prepared by extrusion molding, in which the composite consists of fibers, polymers, and chemical agents that are mixed in different proportions. Composites can exhibit high strength and low density. The recycled fibers can improve the utilization rate and solve agricultural waste problems.

Reinforced wood plastic composites made with natural fibers are applied in many fields; these composites have excellent hydrophobic properties and high fire resistance properties, which allows them to be used in environmental facilities, automotive interiors, household products, etc. (Pickering et al. 2016). The good interfacial adhesion has a positive effect on the mechanical and physical properties of composites (Jumaidin et al. 2017; Nadlene et al. 2018). Rice husk fibers are widely used because they can absorb organic compounds (Hubadillah et al. 2017; Battegazzore et al. 2018; Pakravan et al. 2018). Lignocellulosic fibers consist of cellulose, hemicelluloses, and lignin; the existence of hydroxyl groups (HO-) on the carbohydrates of the fibers can interfere with its interfacial bonding with hydrophobic polymer matrices (Jehdaramarn et al. 2018).

Pretreatment methods can improve the interfacial bonding quality. Physical treatment methods include hydrothermal treatment (Wang et al. 2017), microwave 
processing (Kostas et al. 2017; Lu et al. 2017; Jhodkar et al. 2018), steam explosion method (Martino et al. 2017), etc. Chemical treatment methods include acid treatment (Zhou et al. 2017), alkaline treatment (Chandrasekar et al. 2017), acetylation treatment (Joffre et al. 2017), benzoylation treatment (Santulli et al. 2009), etc. Recently, many investigators have studied different pretreatment methods; the reports indicate that treated fibers can improve the physical and mechanical properties of fiber-plastic composites (Cheison and Kulozik 2017). The rough surfaces of the fibers can easily combine with matrix (plastic), whereby the mechanical and thermal properties of the resulting composites are improved.

In this work, the effect of four treatment methods on fibers reinforced composites was studied, and the physical and mechanical properties of composites were analyzed. The optimum conditions for the four pretreatment methods were determined from earlier experimental work (Manikandan et al. 2017; Palola et al. 2017; Fei et al. 2018; Mayandi et al. 2018). The best pretreatment method was determined by comparing the four pretreatment methods. The microstructure of rice husk fibers was observed by scanning electron microscopy (SEM), the chemical functional groups were characterized by Fourier transform infrared (FTIR) spectroscopy, and the crystallinity of the cellulose in the fibers were examined by X-ray diffraction (XRD). The goal is to find a pretreatment method that can effectively extend the actual applications of composites made with RHFs.

\section{EXPERIMENTAL}

\section{Materials}

Rice husk fibers (RHFs) were obtained from Shijiazhuang Feiteng Agricultural Products Co., Ltd., China. Polyvinyl chloride (PVC), SG-5 PVC, was purchased from Shanghai Tianbin Trading Co., Ltd., China. The following chemical components were purchased from Jining Haoyi Chemical Co., Ltd., China: 603 non-toxic $\mathrm{Ca} / \mathrm{Zn}$ composite stabilizer and H-108 PE wax. All chemical reagents were purchased from Shanghai Shiyi Chemical Reagent Co., Ltd., China.

\section{Pretreatment Methods}

\section{Hydrothermal treatment (HT)}

The HT procedure consisted of two steps. First, the RHFs were heated at $90{ }^{\circ} \mathrm{C}$ for $2 \mathrm{~h}$ in deionized water. Afterwards, the filtered fibers were dried at $105^{\circ} \mathrm{C}$ for $24 \mathrm{~h}$ in a DHG-9140A electro-thermostatic drum-wind drying oven (Nanjing Dongmai Scientific Instrument Co., Ltd., China) (Fei et al. 2018).

\section{Microwave treatment (MT)}

The MT procedures consisted of three steps. First, the RHFs were immersed into deionized water for $12 \mathrm{~h}$. Next the mixture was placed into a SX-25-10 Box Resistance Furnace (Shanghai Boluo Experimental Equipment Co., Ltd., China) at medium heat setting $(70 \%, 400-500 \mathrm{~W})$ for $2 \mathrm{~min}$; this was repeated five times. Finally, the treated fibers were dried at $100{ }^{\circ} \mathrm{C}$ for $6 \mathrm{~h}$ (Palola et al. 2017).

\section{Alkali treatment $(A T)$}


RHFs were immersed in $4 \%$ sodium hydroxide solution in water. The mixture was mixed at $300 \mathrm{rpm}$ for $8 \mathrm{~h}$ in a water bath set at $40{ }^{\circ} \mathrm{C}$. Then the treated fibers were washed with deionized water until filtrate $\mathrm{pH}$ was almost 7; afterwards, the filtered fibers were dried at $100{ }^{\circ} \mathrm{C}$ for $6 \mathrm{~h}$ (Manikandan et al. 2017).

\section{Benzoylation treatment (BT)}

The fibers were soaked for $30 \mathrm{~min}$ in $18 \%$ sodium hydroxide solution. Then the slurry was drained; the fibers were washed with deionized water and then filtered. The fibers were placed into $10 \%$ sodium hydroxide solution and stirred. Benzoyl chloride (50 $\mathrm{ml}$ ) was added and the slurry stirred for $15 \mathrm{~min}$. The reacted fibers were filtered, washed and dried. The treated fibers were immersed in ethanol for $1 \mathrm{~h}$ to remove excess benzoyl chloride. The ethanol-rinsed fibers were filtered and then dried at $100{ }^{\circ} \mathrm{C}$ for $6 \mathrm{~h}$ (Mayandi et al. 2018).

\section{Sample preparation}

The rice husk fiber powder (100 mesh) was dried in a DHG-9140A electrothermostatic drum-wind drying oven (Nanjing Dongmai Scientific Instrument Co. Ltd., Jiangsu, China), the temperature and time set at $90^{\circ} \mathrm{C}$ and $12 \mathrm{~h}$. The mixture (treated fibers, PVC, stabilizer, PE wax and maleic anhydride grafted polyvinyl chloride) added at the proportion of 100:100: 8:5:3, then placed into a SBH-5L 3D linkage mixer (Nanjing Xinbao Mechanical and Electrical Industry Co., Ltd., China). The composites were prepared by a RM200C conical twin-screw extruder (Harbin Hapro Electric Technology Co., Ltd., China). The temperature and speed of the extruder were controlled at 150 to $165^{\circ} \mathrm{C}$ and $20 \mathrm{rpm}$, respectively. The size of test samples was controlled to $100 \mathrm{~mm} \times 10$ $\mathrm{mm} \times 7 \mathrm{~mm}$.

\section{Accelerated Soil Aging Experiments}

Based on previous work (Wang et al. 2019), the aging experiment of composites was performed at soil temperature $65^{\circ} \mathrm{C}+$ soil $\mathrm{pH} 2.5+$ soil moisture content $45 \%+$ soil porosity 3:7 (the mass ratio of thick and thin). Accelerated soil aging experiments were conducted in three stages. First, diatomite of interactive particle sizes (380 to $830 \mu \mathrm{m}$ and $75 \mu \mathrm{m}$ ) was mixed using a SBH-5L 3D linkage mixer (Nanjing Xinbao Mechanical and Electrical Industry Co. Ltd., China); the mixture was placed into a LHS-80HC-I humidity alternating tester (Shanghai Yiheng Scientific Instrument Co., Ltd., China) at 90\% humidity for $7 \mathrm{~d}$. Next, a $2.5 \mathrm{pH}$ solution was prepared. The chemical reagents included $\mathrm{NaCl}(0.23 \mathrm{~g} / \mathrm{L}), \mathrm{Na}_{2} \mathrm{SO}_{4}(0.07 \mathrm{~g} / \mathrm{L}) ; \mathrm{MgSO}_{4}(0.09 \mathrm{~g} / \mathrm{L}) ; \mathrm{CaCl}_{2}(0.05 \mathrm{~g} / \mathrm{L}) ; \mathrm{KNO}_{3}(0$. $33 \mathrm{~g} / \mathrm{L})$; and $\mathrm{NaHCO}_{3}(0.07 \mathrm{~g} / \mathrm{L})$. Finally, the diatomite was placed into the solution and uniformly stirred (Lin and Yang 2007; Kositchaiyong et al. 2014). The test composite samples were placed into the simulated soil at $10 \mathrm{~cm}$ depth with each sample separated by $2 \mathrm{~cm}$. The experiment was heated by a HH-600 thermostatic water bath (Shanghai Baidian Instrument Equipment Co., Ltd., China), and the temperature was controlled at 1 ${ }^{\circ} \mathrm{C}$. Once the aging period had past, the aged samples were dried constant mass was attained.

\section{Characterization}

Physical and mechanical properties of composites

Flexural and impact tests were conducted on composite samples using a CMT6104 electronic universal testing machine (MTS Industrial Systems Co., Ltd., 
China) in accordance to the following Standard: ISO13061-10(2017).

The color of the samples was characterized using a HP-200 precise color meter (Shanghai Chinaspec Optoelectronics Technology Co., Ltd., China), which reported color coordinates in the CIE 1976 color space $(L * a * b *)$,

$$
\Delta E=\sqrt{\Delta L^{2}+\Delta a^{2}+\Delta b^{2}}
$$

where $\Delta E, \Delta L, \Delta a$, and $\Delta b$ represent the difference in color $(E)$, color lightness $\left(L^{*}\right)$, red to green $(a *)$, and yellow to blue $\left(b^{*}\right)$.

Five characterization measurements per sample were made, and the average value was reported. Measurements were made at room temperature $\left(25 \pm 1{ }^{\circ} \mathrm{C}\right)$.

Fourier transform infrared (FTIR) and X-ray diffraction (XRD) spectra analysis

Fourier transform infrared (FTIR) spectra were measured using a Nicolet iS10 spectrometer (Thermo Fisher Scientific Co., Ltd., China). The wavenumber range recorded was from 400 to $4000 \mathrm{~cm}^{-1}$ with a resolution of $4 \mathrm{~cm}^{-1}$; each recording was made up of 16 scans in the absorbance mode. The amount of each composite sample scanned was $0.002 \mathrm{~g}$.

The crystallinity of the RHFs was measured using an X'Pert PRO X-ray diffractometer (PANalytical B.V., Netherlands) that used $\mathrm{Cu}-\mathrm{K} \alpha$ radiation $(\lambda=0.15406$ $\AA$ ), and operated at $40 \mathrm{kV}$ and $40 \mathrm{~mA}$. Samples were scanned at a rate of $0.33 \% \mathrm{~min}$ with a $2 \theta$ range of $0^{\circ}$ to $\left.90^{\circ}\right)$. The crystallinity index $(\mathrm{Cr} I)$ of the cellulose was calculated as follows,

$$
C r I=\left[1-\left(I_{a m} / I_{002}\right)\right] \times 100
$$

where $I_{002}$ is maximum intensity of the diffraction peak $(2 \theta)$ of $22.5^{\circ}$, and $I_{a m}$ is the minimal intensity diffraction peak at $18^{\circ}$.

\section{Microstructure analysis}

Images of the composites after tensile testing were obtained using a S-4800 scanning electron microscope (SEM, Hitachi., Ltd., Japan). The interfacial bonding of fibers with the matrix was observed using SEM images.

\section{RESULTS AND DISCUSSION}

\section{Fourier Transform Infrared (FTIR) and X-ray Diffraction (XRD) Spectra}

FTIR was used to further investigate the changes in the chemical functional groups (Fig. 1), which represented the composite samples before and after the soil aging tests. The stretching vibration peaks that appeared at 3420 to $3410 \mathrm{~cm}^{-1}$ were attributed to hydroxyl $(-\mathrm{OH})$ groups in cellulose and hemicelluloses. Asymmetric stretching vibration peaks that appeared in the range of 2930 to $2850 \mathrm{~cm}^{-1}$ were ascribed to $\mathrm{C}-\mathrm{H}$ groups in cellulose. Stretching vibration peaks that appeared in the range of 1745 to $1710 \mathrm{~cm}^{-1}$ were ascribed to $\mathrm{C}-\mathrm{O}$ groups in lignin and hemicelluloses. Typical stretching vibration peaks that occurred in the range of 1250 to $1230 \mathrm{~cm}^{-1}$ were attributed to lignin. The stretching vibration peaks that appeared in the range 1100 to $990 \mathrm{~cm}^{-1}$ were attributed to C-O groups on the polysaccharides. FTIR spectra of the four treated composites had similar chemical functional groups after soil aging for $21 \mathrm{~d}$ with no notable differences. These 
observations indicated that the chemical structure of composites was not affected by the simulated soil aging. These observations were similar to the results reported by Wang et al. (2018), who provided a theoretical analysis of the chemical functional groups in PVC composites.
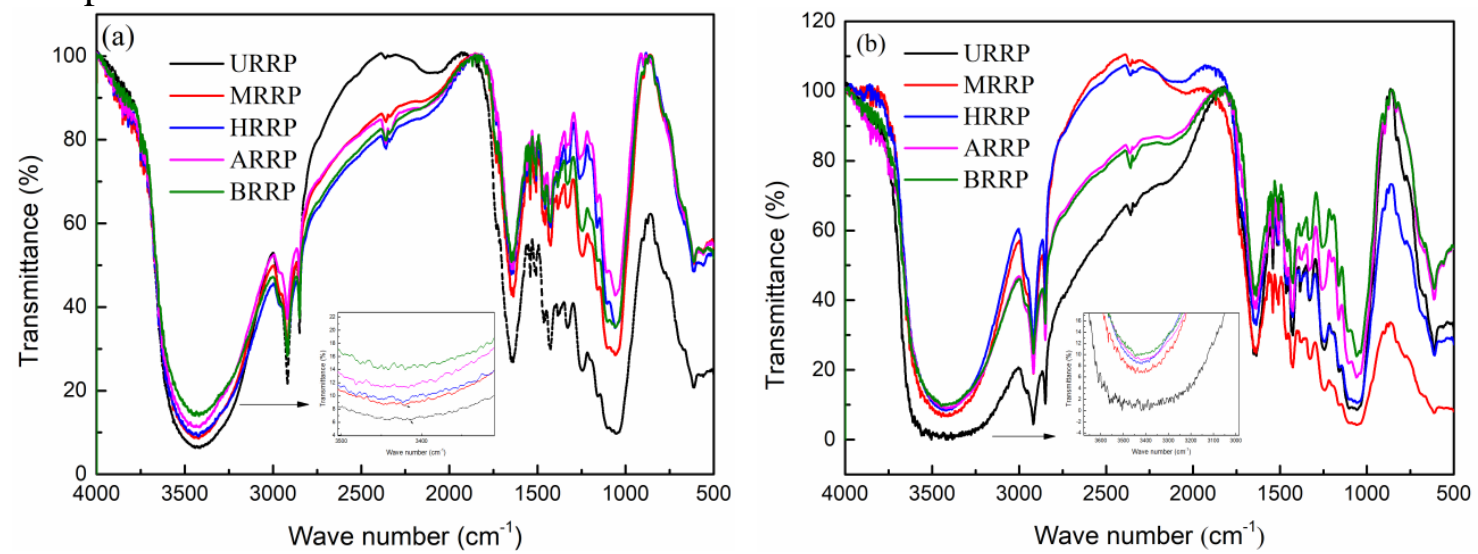

Fig. 1. FTIR spectra of the composites

In general, the peak at $3410 \mathrm{~cm}^{-1}$ was less intense after HT, MT, AT, and BT when compared to untreated composites. Benzoylation treatment reduced the amount of hydroxyl groups and improved the adhesion between the fibers and the polymer matrix. In addition, alkali treatment reduced the polarity and hydrophilicity of the fibers. The four fiber pretreatment methods each had a positive effect on fiber-matrix interfacial bonding. It was obvious that the reduction in hydroxyl groups followed the order (from highest to lowest): benzoylate-treated RHFs reinforced PVC (BRRP) > alkali-treated RHFs reinforced PVC (ARRP) > hydrothermal-treated RHFs reinforced PVC (HRRP) > microwave-treated RHFs reinforced PVC (MRRP) > untreated RHFs reinforced PVC (URRP).

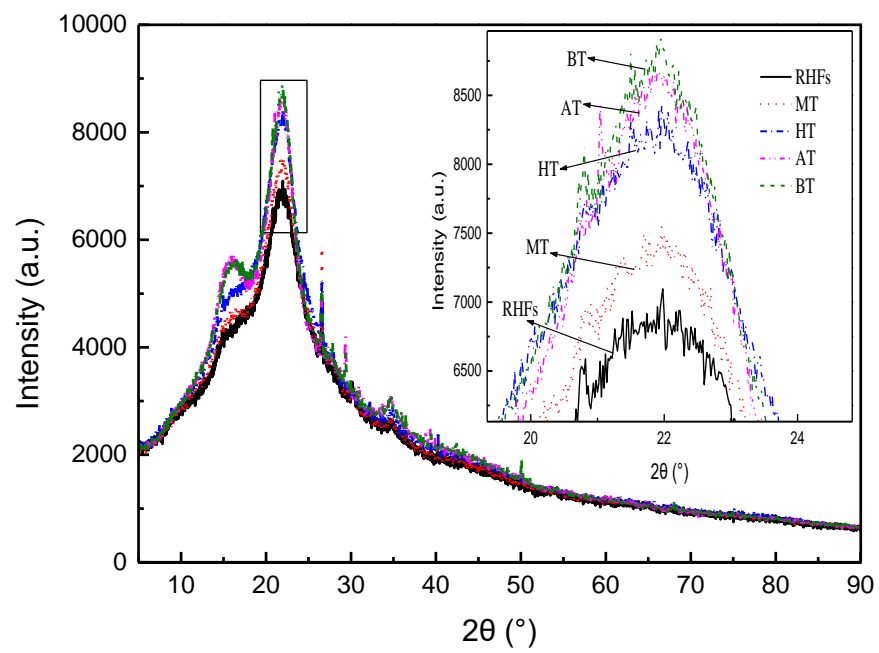

Fig. 2. XRD spectra of untreated rice husk fiber (RHFs) compared to MT, HT, AT, and BT RHFs

As a lignocellulosic fiber, the RHFs consisted of cellulose, hemicelluloses, and lignin. A change in cellulose crystallinity represents a change to the fiber structure. Figure 2 shows the XRD patterns of RHFs after HT, MT, AT, and BT. The diffraction peak at $2 \theta=22^{\circ}$ corresponds to the [002] crystalline lattice plane of cellulose I ( $\mathrm{Hu}$ and Guo 2015). 
The crystallinity indexes of RHFs after MT, HT, AT and BT were 33.8\%, 38.2\%, $41.7 \%$, and $43.2 \%$, respectively, as compared to untreated RHFs at $30.6 \%$. The crystallinity indices for the four pretreatment methods were higher than the untreated RHFs; this observation was attributed to the removal of non-cellulosic constituents during the RHF pretreatment. The maximum crystallinity index $(43.2 \%)$ was observed with the benzoylation treatment. The pretreatment methods can remove the hemicellulose and lignin.

\section{Mass Loss and Color Analyses of Composites}

The cumulative mass loss and color analyses of the composites are shown in Fig. 3 . The cumulative mass loss was higher as the soil aging period increased; the rate of the mass loss slowed as the soil contact time increased. When the time reached $21 \mathrm{~d}$, the total mass losses of BRRP, ARRP, HRRP, and MRRP samples were 1.2\%, 1.4\%, $2.1 \%$ and $2.4 \%$, respectively, versus $2.9 \%$ for the URRP (i.e., control). BRRP had the lowest total mass loss. This was attributed to the reduction of the hydroxyl groups during the fiber pretreatment. The hydrophilicity of the BR fibers was reduced when compared to the untreated fibers. The RHFs were easily coated by the PVC matrix, which improved the interfacial bonding that led to less mass loss.
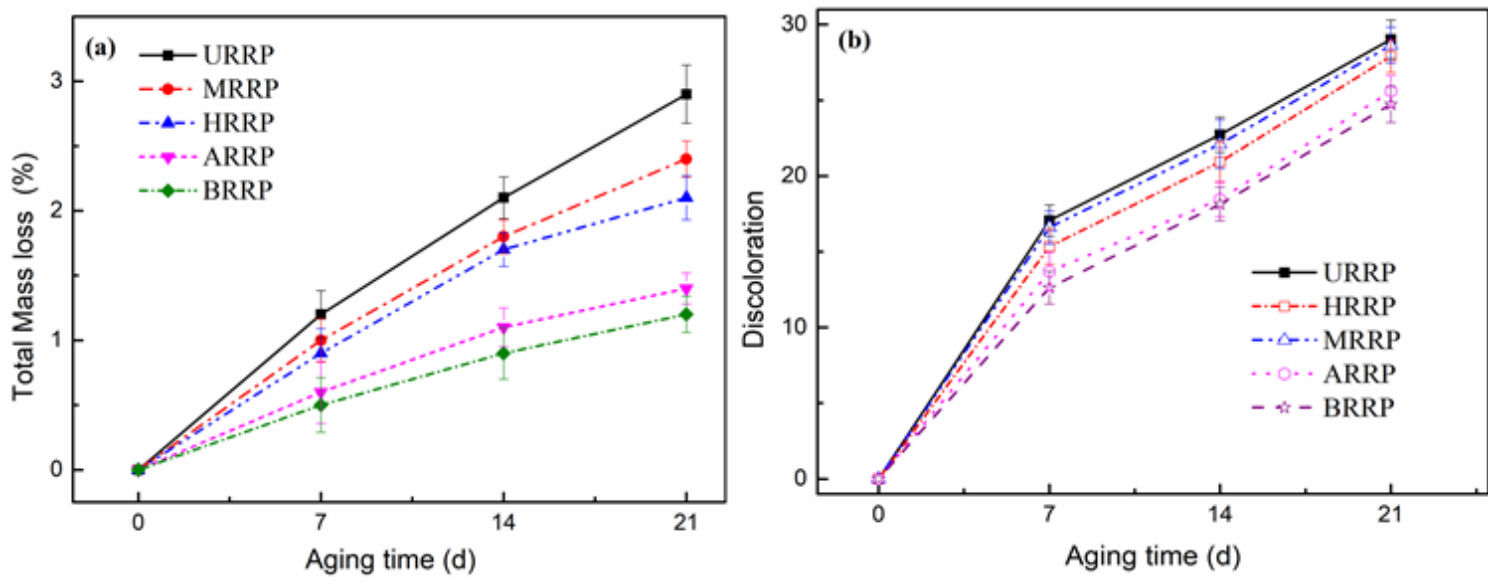

Fig. 3. The mass loss rate and discoloration of composites

The discoloration of the composites during the accelerated soil aging experiments is shown in Fig. 3b. Discoloration was affected by the four pretreatment methods. The $\Delta E^{*}$ values after $21 \mathrm{~d}$ for BRRP, ARRP, HRRP, MRRP, and URRP were 24.7, 25.6, 27.9, 28.6, and 29.1, respectively. BRRP had the smallest discoloration value after $21 \mathrm{~d}$ of aging. These trends are similar to the mass losses reported in Fig. 3a; the four pretreatment methods can slow down the discoloration effectively. Benzyolation treatment was the most effective method, the two-phase combination ability was improved by four pretreatment methods, and fibers were well coated by plastic matrix. Good interfacial bonding lead to well ultimate properties. The SEM images of the bonding of the matrix with the fibers are shown in Fig. 4.

\section{Tensile Fracture Surfaces Analysis of Composites}

Interfacial bonding plays an important role in the performance of composites, such as mechanical, physical and thermal properties. The effect of treated fibers reinforced composites was shown at Fig. 4 . When the aging time was $21 \mathrm{~d}$, interfacial 
bonding was weakened in comparison to the original composites. Micro-cracks were evident at the interface of composites, which apparently allowed water molecules to attack the interface of composites. The worse interfacial bonding led to poor physical and mechanical properties.

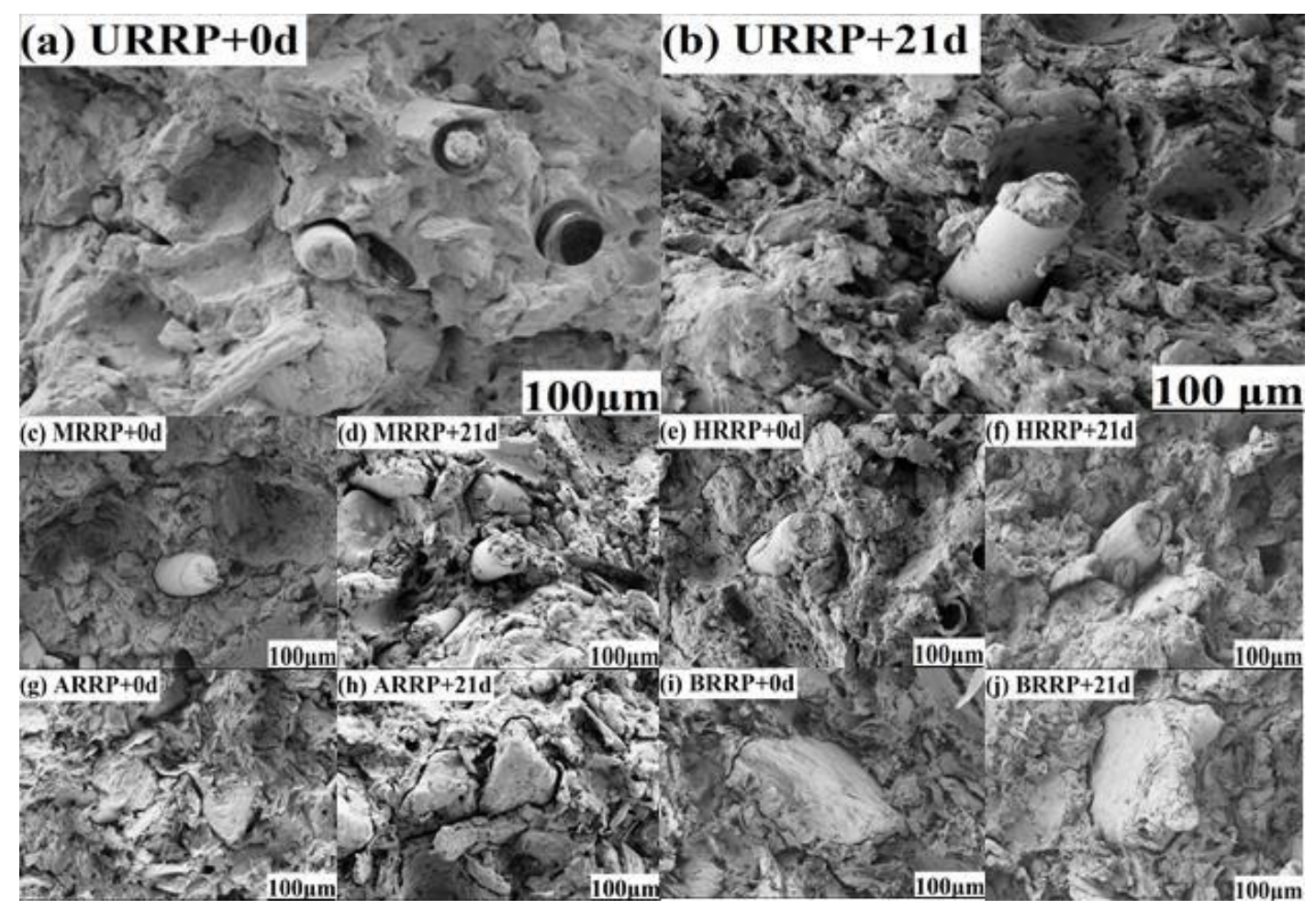

Fig. 4. Tensile fracture surfaces of composites (Wang et al. 2019)

Compared to the URRP composite, the interfacial bonding of the composites made with the fibers pretreated by the four different methods was improved, with the BRRP composite exhibiting the best performance. It was concluded that the interfacial bonding of BT fibers with the PVC matrix was the highest when compared to other reinforced composites using other pretreated fibers. No noticeable gaps appeared at the fracture surfaces of composites. The surface of benzoylation treated fibers was rougher than before pretreatment, which led to stronger interfacial bonding between the PVC matrix and the fibers. The adhesion of the fibers was improved by reducing the amount of hydroxyl groups. 

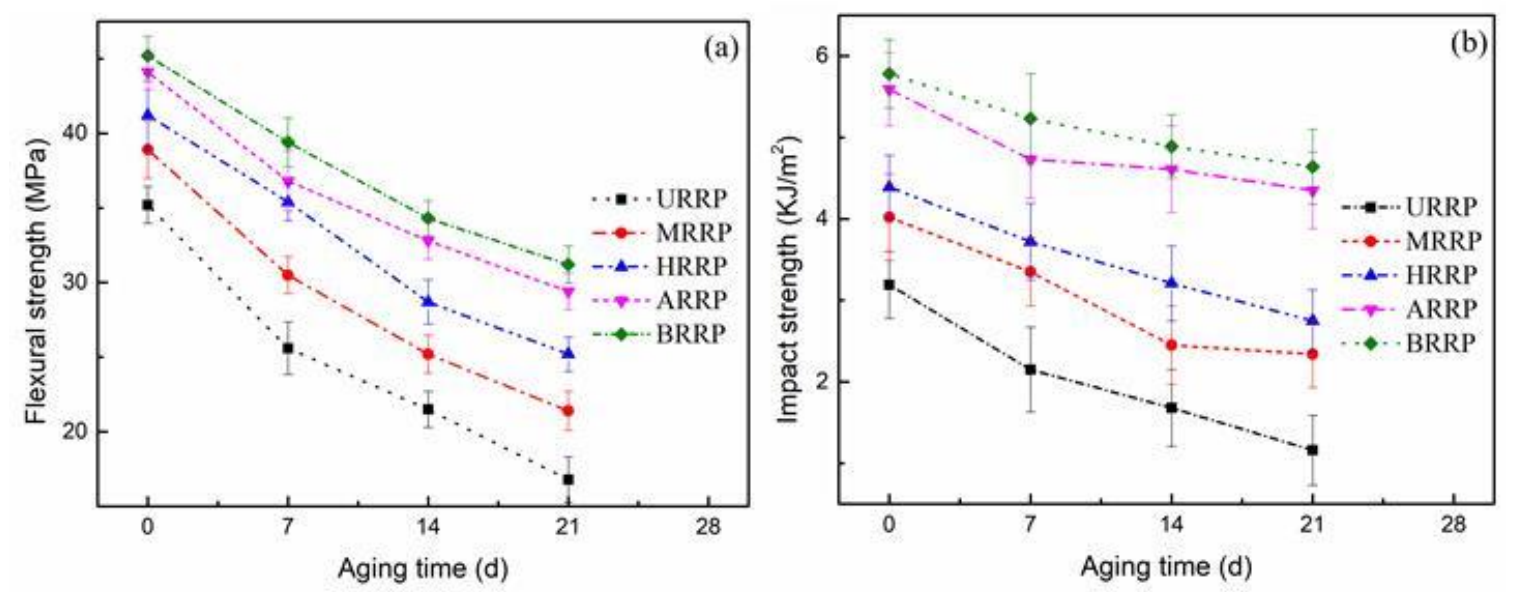

Fig. 5. Mechanical properties of the composites

\section{Analysis of Physical and Mechanical Properties of Composites}

The flexural and impact strength of the RHFs/PVC composites are summarized in Fig. 5. There was a slight decrease after $21 \mathrm{~d}$ of soil aging. When the aging period approached $21 \mathrm{~d}$, the BRRP sample had the highest values of flexural (31.2 MPa) and impact strength $\left(4.64 \mathrm{~kJ} / \mathrm{m}^{2}\right)$. The trend for these properties for the RHFs/PVC composites followed order (from highest to lowest): BRRP $>$ ARRP $>$ HRRP $>$ MRRP $>$ URRP. This is because long soil aging leads to weak interfacial bonding. Micro-cracks came into being at the interface of composites. Water molecules can attack the internal structure of composites, such that the micro-cracks gradually became larger than before. Re-bounded interfacial bonding cannot absorb more energy than before; thus, the ultimate properties of composites have a decreasing trend with the increasing of soil aging time (Dhakal et al. 2007). Four pretreatment methods made a deep influence on the interfacial bonding. Treated fibers can tightly combine with the PVC matrix, and good interfacial bonding improved the soil aging resistance ability. It is worth noting that benzoylation treatment was the best pretreatment method in four treatment methods, surface modification improved the compatibility of fibers and matrix effectively. This phenomenon of interfacial bonding can explain the observed SEM images (Fig. 4).

\section{CONCLUSIONS}

1. When the PVC composite samples were subjected to $21 \mathrm{~d}$ of soil aging time, the physical and mechanical properties of the composites were degraded.

2. The chemical pretreatment methods (benzoylation and alkali treatment) had a higher positive effect on the composite's physical and mechanical properties than the physical pretreatment methods (hydrothermal and microwave treatment).

3. The degree of effectiveness of the four pretreatment methods are listed (from highest to lowest): benzoylation-treated RHFs reinforced PVC (BRRP) > alkali-treated RHFs reinforced PVC $($ ARRP) $>$ hydrothermal-treated RHFs reinforced PVC (HRRP) > microwave-treated RHFs reinforced PVC (MRRP) > untreated RHFs reinforced PVC (URRP).

4. Benzoylation pretreatment improved the interfacial fiber-matrix, which mitigated 
losses of physical and mechanical properties of the resulting composites when subjected to accelerated soil aging

\section{ACKNOWLEDGEMENTS}

This work was financially supported by the National Key Technology Support Program (2011BAD20B202-2), the Fundamental Research Funds for the Central Universities (Y0201800586) and the Natural Science Foundation of the Jiangsu Higher Education Institutions of China (Grant No.18KJD430002)

\section{REFERENCES CITED}

Battegazzore, D., Alongi, J., Duraccio, D., and Frache, A. (2018). "All natural highdensity fiber-and particleboards from hemp fibers or rice husk particles," J. Polym. Environ. 26(4), 1652-1660. DOI: 10.1007/s10924-017-1071-9.

Chandrasekar, M., Ishak, M. R., Sapuan, S. M., Leman, Z., and Jawaid, M. (2017). “A review on the characterization of natural fibres and their composites after alkali treatment and water absorption," Plast. Rubber Compos. 46(3), 119-136. DOI: 10.1080/14658011. 2017.1298550

Cheison, S.C., and Kulozik, U. (2017). "Impact of the environmental conditions and substrate pre-treatment on whey protein hydrolysis: A review," Crit. Rev. Food Sci. 57(2), 418-453. DOI: 10.1080/10408398.2014.959115

Dhakal, H. N., Zhang, Z. Y., and Richardson, M. O. W. (2007). "Effect of water absorption on the mechanical properties of hemp fibre reinforced unsaturated polyester composites." Compos Sci Technol, 67(7), 1674-1683.

DOI:10.1016/j.compscitech.2006.06.019

Fei, J., Luo, D., Wang, H., Li, H., Huang, J., Luo, W., and Duan, X. (2018). "Effect of nano- $\mathrm{SiO}_{2}$ particles on the carbon fabric/resin friction materials by microwavehydrothermal treatment," J. Compos. Mater. 52(2), 245-252. DOI: $10.1177 / 0021998317705441$

$\mathrm{Hu}$, J., and Guo, M. (2015). "Influence of ammonium lignosulfonate on the mechanical and dimensional properties of wood fiber biocomposites reinforced with polylactic acid," Ind. Crop. Prod. 78, 48-57. DOI:10.1016/j.indcrop.2015.09.075.

Hubadillah, S. K., Othman, M. H. D., Harun, Z., Ismail, A. F., Rahman, M. A., and Jaafar, J. (2017). "A novel green ceramic hollow fiber membrane (CHFM) derived from rice husk ash as combined adsorbent-separator for efficient heavy metals removal," Ceram. Int. 43(5), 4716-4720. DOI: 10.1016/j.ceramint.2016.12.122

Jehdaramarn, A., Pornsuwan, S., Chumsaeng, P., Phomphrai, K., and Sangtrirutnugul, P. (2018). "Effects of appended hydroxyl groups and ligand chain length on copper coordination and oxidation activity," New J. Chem. 42(1), 654-661. DOI: 10.1039/C7NJ03113K

Jhodkar, D., Amarnath, M., Chelladurai, H., and Ramkumar, J. (2018). "Experimental investigations to enhance the machining performance of tungsten carbide tool insert using microwave treatment process," J. Braz. Soc. Mech. Sci. 40(4), 200. DOI: 10.1007/s40430-018-1096-6

Joffre, T., Segerholm, K., Persson, C., Bardage, S. L., Hendriks, C. L. L., and Isaksson, 
P. (2017). "Characterization of interfacial stress transfer ability in acetylation-treated wood fibre composites using X-ray microtomography," Ind. Crop. Prod. 95, 43-49. DOI: 10.1016/j.indcrop.2016.10.009

Jumaidin, R., Sapuan, S. M., Jawaid, M., Ishak, M. R., and Sahari, J. (2017). “Thermal, mechanical, and physical properties of seaweed/sugar palm fibre reinforced thermoplastic sugar palm starch/agar hybrid composites," Int. J. Biol. Macromol. 97, 606-615. DOI: 10.1016/j.ijbiomac.2017.01.079

Koohestani, B., Ganetri, I., and Yilmaz, E. (2017). "Effects of silane modified minerals on mechanical, microstructural, thermal, and rheological properties of wood plastic composites," Compos. Part B 111, 103-111. DOI:

10.1016/j.compositesb.2016.12.021

Kositchaiyong, A., Rosarpitak, V., Hamada, H., and Sombatsompop, N. (2014). "Antifungal performance and mechanical-morphological properties of PVC and wood/PVC composites under UV-weathering aging and soil-burial exposure," Int. Biodeterior. Biodegrad. 91, 128-137. DOI: 10.1016/j.ibiod.2014.01.022

Kostas, E. T., Beneroso, D., and Robinson, J. P. (2017). "The application of microwave heating in bioenergy: A review on the microwave pre-treatment and upgrading technologies for biomass," Renew. Sust. Energy Rev. 77, 12-27. DOI: 10.1016/j.rser.2017.03.135

Lin, Y. Z., and Yang, D. J. (2007). Aging and Aging Control Theory, China Petrochemical Press, Beijing.

Lu, G. M., Li, Y. H., Hassani, F., and Zhang, X. (2017). "The influence of microwave irradiation on thermal properties of main rock-forming minerals," Appl. Therm. Eng. 112, 1523-1532. DOI: 10.1016/j.applthermaleng.2016.11.015

Manikandan, N., Morshed, M. N., Karthik, R., Al Azad, S., Deb, H., Rumi, T.M., and Ahmed, M.R. (2017). "Improvement of mechanical properties of natural fiber reinforced jute/polyester epoxy composite through meticulous alkali treatment," Am. J. Curr. Org. Chem. 3(1), 9-18.

Martino, D.C., Colodette, J. L., Chandra, R., and Saddler, J. (2017). "Steam explosion pretreatment used to remove hemicellulose to enhance the production of a eucalyptus organosolv dissolving pulp," Wood Sci. Technol. 51(3), 557-569. DOI: 10.1007/s00226-016-0889-y

Mayandi, K., Rajini, N., Pitchipoo, P., Winowlin Jappes, J.T., and Varada Rajulu, A. (2018). "Properties of untreated and chemically treated Cissus quadrangularis natural fibers and their composites with polyester as the matrix," Polym. Compos. 39(3), 876886. DOI: $10.1002 /$ pc.24011

Mei, C., Sun, X., Wan, M., Wu, Q., Chun, S. J., and Lee, S. (2017). “Coextruded wood plastic composites containing recycled wood fibers treated with micronized copperquat: Mechanical, moisture absorption, and chemical leaching performance," Waste Biomass Valori, 1-8. DOI: 10.1007/s12649-017-9992-z

Nadlene, R., Sapuan, S. M., Jawaid, M., Ishak, M. R., and Yusriah, L. (2018). "The effects of chemical treatment on the structural and thermal, physical, and mechanical and morphological properties of roselle fiber-reinforced vinyl ester composites," Polym. Compos. 39(1), 274-287. DOI: 10.1002/pc.23927

Pakravan, H. R., Jamshidi, M., and Jeddi, A. A. (2018). "Combination of ground rice husk and polyvinyl alcohol fiber in cementitious composite," J. Environ. Manage. 215, 116-122. DOI: 10.1016/j.jenvman.2018.03.035

Palola, S., Sarlin, E., Azari, S. K., Koutsos, V., and Vuorinen, J. (2017). “Microwave 
induced hierarchical nanostructures on aramid fibers and their influence on adhesion properties in a rubber matrix," Appl. Surf. Sci. 410, 145-153. DOI:

10.16/j.apsusc.2017.03.070

Pickering, K. L., Efendy, M. A., and Le, T. M. (2016). “A review of recent developments in natural fibre composites and their mechanical performance," Compos Part A-Appl $S, 83,98-112$. DOI:10.1016/j.compositesa.2015.08.038

Santulli, C., Marzinotto, M., Mazzetti, C., and Thomas, S. (2009). "Influence of content and diameter of fibres and chemical treatment on the dielectric properties of oil palm fibres-rubber composites," Sci. Eng. Compos. Mater. 16(2), 77-88. DOI: 10.1515/SECM.2009.16.2.77

Wang, L., Li, A., and Chang, Y. (2017). "Relationship between enhanced dewaterability and structural properties of hydrothermal sludge after hydrothermal treatment of excess sludge," Water Res. 112, 72-82. DOI: 10.1016/j.watres.2017.01.034

Wang, W., Han, Q., Li, X., Peng, X., and Qian, W. (2018). "Preparation and characterization of PVC matrix composites with biochemical sludge," J. Polym. Environ. 1-5. DOI: 10.1007/s10924-018-121-y

Wang, L., and He, C. X. (2019). "Characterization of rice husk fiber-reinforced polyvinyl chloride composites under accelerated simulated soil conditions," INT. J. POLYM. SCI, 2019. DOI:10.1155/2019/5409821

Zhou, E., He, Y., Ma, X., Liu, G., Huang, Y., Chen, C., and Wang, W. (2017). "Study of the combination of sulfuric acid treatment and thermal regeneration of spent powdered activated carbons from decolourization process in glucosamine production," Chem. Eng. Process. 121, 224-231. DOI: 10.1016/j.cep.2017.09.008

Article submitted: August 27, 2018; Peer review completed: October 28, 2018; Revised version received and accepted; November 1, 2018; Published: November 8, 2018.

DOI: $10.15376 /$ biores.14.1.59-69

Erratum: February 24, 2020: HRRP data was revised and new Figure 1b was updated accordingly. The new data does not change the conclusions of the paper. 